\title{
Cultural Differences in Chinese and American Address Forms
}

\author{
Yu Chen \\ Foreign Languages School of Henan University of Technology \\ Zhengzhou 450052, Henan, China \\ E-mail: chy-yhq@163.com
}

\begin{abstract}
Address behavior is governed by politeness phenomenon which is culturally bound. This paper attempts to draw a cross-cultural comparison between Chinese and English address forms and, going beneath the surface, explore the cultural differences in value systems and their underlying philosophical sources. The study will help people develop a fuller understanding of the meanings of the address terms, and of the polite intention in social contacts so as to facilitate cross-cultural communication.
\end{abstract}

Keywords: Address form, Cultural difference, Cross-cultural communication

Address phenomenon is important as well as frequent in social interactions. Appropriate address behavior is crucial for effective communication and successful maintenance of interpersonal relationships. Normally, address behavior is governed by politeness phenomenon which is culturally bound. Misunderstanding and misinterpretation can lead to feelings of offence, insult, and suspicion on the individuals involved, which will result in break-down in cross-cultural communication. For instance, nonnative speakers of English often express their surprise at the wide use or distribution of reciprocal first naming among people in the U.S. This change from an address form employed to define intimate relationships within a family or among close friends or business associates to the one used to define general relationships between strangers, between people of asymmetrical age and occupational status, between students and professors, and between young people and their seniors, has been quite a recent development which has naturally stimulated cross-cultural studies of address behavior in different countries.

\section{Different Usage of Chinese and American Address Forms}

Based on studies by Chen Songcen (1989) and Quirk (1985), there are six types of address forms: kinship terms, proper names, titles (occupational, official and social), pronouns, no-naming and others (terms of endearment and derogation, indefinite pronouns, nominal phrases and nominal clauses). Although the six categories of address forms exist in both languages, they vary greatly in contents and usage patterns. Besides, although social factors like age, kinship, acquaintances, generation, rank and setting and the principles governing politeness strategies are universal, the linguistic possibilities for the realization of politeness strategies are language specific, that is, different factor may carry different weight in the choice of address strategy in different languages. When comparing the two flow charts designed respectively by American linguist Ervin-Tripp ( 1972, p226-7) and Chinese Zhu Wanjin (1984, p326), it is not difficult to find that in Chinese address system, order of seniority and age play an important part in their choice of proper address forms especially when addressing relatives, neighbors and seniors. However, in American English address system, seniority and age exert influence mainly on people of higher generation (15 years older) in kinships, while first names instead of honorific titles can be used even when addressing older generations among friends and colleagues.

Let's now summarize the major differences in Chinese and American English address use as follows:

- Recently, the trend of many English-speaking people has been to address others by using the first name than using titles like Mr., Mrs., or Miss even when people meet for the first time. This applies not only to people of roughly the same age, but also of different ages. It is not a sign of disrespect. However, this is quite counter to Chinese custom.

- Kinship terms play an important part in Chinese address system. Age, generation and order of seniority are regarded as far more important than those in American system.

- The use of a person's title, office or occupation is quite common in Chinese address system. But one seldom hears English speakers addressing others as Bureau Director Smith, Manager Jackson, Principal Morris. In English, only a few occupations or titles would be used which include Doctor, Judge, Governor, Mayor and 
Professor.

- Due to the complexity of Chinese address system, there do exist some problems in finding the English equivalents of some Chinese terms of address. For instance, how to address a teacher has long been a problem. Should it be Teacher or Teacher Zhang? Neither of these is in keeping with English custom. Or should we simply follow the English custom and call the teacher Mr. Zhang, Mrs. Yang, Miss Fei, or just his or her first name? All of these would sound terrible to Chinese if school-age youngsters were to do so. Should we say Comrade or Comrade Li? Although terms such as xiansheng and xiaojie can roughly be translated as Mr. or Sir, Miss or Lady, they carry different connotations. In Chinese, xiansheng and xiaojie are honorific titles, while Sir or Mr. is only a very common address form. Therefore, American professors or scholars often prefer to be addressed by their occupational or technical titles such as Professor or Doctor and would be offended if otherwise addressed by Mr.. Prefixes such as lao (Old), xiao (Little) and the suffix lao (Old) are also regarded by Chinese people as showing friendliness or affection or respect. However, the word "lao" (Old) may make an American extremely unhappy. Similarly, while the use of xiaojie (Miss) may please a middle-aged American woman, it may really annoy a Chinese woman. Here again we can see the importance of age, generation and seniority in Chinese address system. What is considered proper and polite in one language may cause embarrassment or disrespect in another.

Now let's go further and try to explore the philosophical sources behind the differences in Chinese and English address use.

\section{Different Cultural Backgrounds and Philosophical Sources}

Since address behavior serves as an indication of social relations between S (i.e. the speaker) and H (Brown \& Gilman, 1990, p.252), it is inevitably a reflection of interpersonal relationship in a specific culture or a certain language context (Du, 1999, p217).

However, interpersonal relationship in the Chinese context is underpinned by Confucianism, especially Ren and $L i$, which lie at the very core of Confucianism. It is well-acknowledged that $\mathrm{Li}$ and Ren, which can hardly be appropriately translated into English, virtually determine almost all aspects of the Chinese life- they have become the collective unconsciousness for the Chinese programming their social behavior including speech acts such as apologies, compliments, addressing, etc; as well as communicating rules, such as conversational principles, politeness principles, face work, etc. In short, Ren and $L i$ have shaped the way the Chinese behave (Jia, 1999:505-506). Ren serves as the goal of life. Men should be warm and benevolent to others or love them and respect themselves. Self or an individual must merge himself into the group or collective. To some extent, the largeness of heart which Ren renders knows no boundaries as Ren advocates that "within the four seas all men are brothers and sisters." $L i$ serves as a norm or a means for people to achieve ideal manhood or good relationships. It defines almost all the norms or rules for the appropriate conduct and behavior for every social member according to his or her social position. The Chinese society, traditionally speaking, is hierarchical in nature. In a society as such, $L i$ is used as norms and means to maintain this hierarchical social order by differentiating the difference between the emperor and his subjects, father and his sons and daughters, brothers and obligations according to their positions. As a matter of fact, Li advocates nothing but vertical or hierarchical relationships and its essential function is to build social order upon this hierarchical relationships. It functions in the society as law does in the western society.

Now let's examine the history of the United States, which is unique in that the dominant culture is relatively young and was formed primarily through two processes. First, those who originally arrived on the Atlantic coast brought many English values, the English system of law, and the basic organization of commerce that was prevalent during the sixteenth century. Second, these settlers were immediately confronted with a wave of new citizens who arrived through migration. This produced what is sometimes referred to as the "melting pot", "stew", or "mixed salad" metaphor of culture. The shared, desperate desire of the American people to be separated from what was known as the Crown and Divine Rights, as well as from the Church of England, provided the impetus to seek unity. The fundamental American proposition became "Life, Liberty and the pursuit of happiness" for each individual. The environmental factors also had psychological effects on the settlers: after developing habits of survival based on individualism, a lack of formality and efficiency, they soon also developed thought patterns, beliefs, values, and attitudes attuned to that environment. Therefore, we can say that unlike Chinese culture, Ren and $L i$ find no place in the western philosophy and religion. What is highly valued in the west is individualism and as a result, equal or horizontal relationship is highly valued. What is advocated is not the obligations and responsibilities ascribed to each member of the society according to his or her social position but humanitarianism and human rights and thus the slogan: everybody is born equal-democracy, liberation of the individual is everybody's wish. 
As we have discussed, the ancient Confucian kinship relationships are an extremely powerful force in Chinese cultural relationship. In contrast to this, a recent United States census accepted fourteen different family types (Ron Scollon \& Suzanne Wong Scollon, 2000, p130), from the traditional extended family to the single parent with adopted child. Kinship is far from being felt as a significant tie among members of society. In many cases, kinship relationships are seen as significant barriers to individual self-realization and progress. The increasingly popular American practice of children calling their parents by first names, for example, would be quite unpleasantly surprising to most Chinese.

In China, authority is respected and listened to and power relationship, in sociolinguistic terms, is highly valued. This emphasis on hierarchical relationship has a two-fold consequence for discourse: from very early in life one becomes subtly practiced in the discourse forms of hierarchical relationship. One learns first to show respect to those above, then, in due time, one learns the forms of guidance and leadership of those who come after. The second consequence is that one comes to expect all relationships to be hierarchical to some extent. If hierarchy is not based on kinship relationship, then it seems to be based on age, experience, education, gender, political affiliation, or one of the many other dimensions of social organization within culture. This relationship is best demonstrated in the use of titles or honorifics when addressing occurs.

\section{Addressing in Cross-cultural Communication}

Addressing takes place so frequently in social interactions that it is an important component of communicative competence. In principle, one cannot expect that the literal translation of the routine expressions of his own language into another will have the same effect in the target language. But in practice, the interference of one's mother tongue in using a foreign language seems to be inevitable for foreign language learner. An American scholar was greatly annoyed when addressed as Mr. instead of Professor by Chinese speakers of English, who actually tried to show respect to him. A female Chinese student in a university of the United States was also annoyed by the term "pet" directed to her from a cleaner. The student thought how that person could treat her as an animal, say, a dog or cat. She was quite unhappy until someone explained the goodwill of the cleaner towards her in using the term. There are more examples in actual interactions.

Since misunderstandings can easily occur, Helen Oatey (1987, p22) suggests that "it is important to consider how addressing is conveyed in English and Chinese, and to what extent there are differences between the two cultures in this respect." It is important to remember that the communication rules are culturally bound. This means that if you want to be successful in intercultural communication, you must know not only the rules of your culture but that of the culture of the person with whom you are interacting as well. If you know the rules, the other person's behavior will make more sense to you and you can alter your behavior to the rules of the culture. Otherwise, you may interpret what you hear according to the rules of your native culture and misunderstand the speaker's intension or even perceive insincerity or offence where none was meant. The key to clear the difficulty is to acquire adequate knowledge of, and to be willing to accept the cultural differences in communication.

In this world with a diversity of cultures, no culture may necessarily be better or worse than another. Cultures are just different from one another. It is the cultural differences that make this world move, grow and enrich itself. Let me end this paper with a beautiful sentence written by Benedict (Samovar, 2000, p78), "God gave to every people a cup, a cup of clay, and from this cup they drank life... They all dipped in the water, but their cups were different."

\section{References}

Brown, R. W., \& Gilman, A. (1990). The pronouns of power and solidarity. In Giglioli, P. P. (Ed.), Language and Social Context. Harmondsworth: Penguin, pp. 252-282.

Chen, S. (1989). A Tentative Exploration of Polite Language. Beijing: Commercial Press.

Du, Xuezeng. (1999). A Tentative Comparison of First Naming Between Chinese and American English. In Hu Wenzhong (ed.) Aspects of Intercultural Communication. Beijing: Foreign Language Teaching and Research Press, pp. 207-219.

Ervin-Tripp, S. (1972). Sociolinguistic rules of address. In J. B. Pride \& J. Holmes (Eds.) Sociolinguistics. London: Penguin, pp. 225-240.

Fang, H. Q. and Heng, J. H. (1983). Social Changes and Changing Address Norms in China. Language in Society, 12(4):495-508.

Jia, Y. X. (1999). Interpersonal Relationship and Intercultural Communication: East and West. In Hu Wenzhong 
(ed.) Aspects of Intercultural Communication. Beijing: Foreign Language Teaching and Research Press, pp. 505-522.

Oatey, H. (1987). The Customs and Language of Social Interaction English. Shanghai: The Shanghai Foreign Language Education Press.

Quirk, R. et al. (1985). A Comprehensive Grammar of the English Language. London: Longman.

Samovar, L. A., Porter, R. E., \& Stefani, L. A. (eds.) (2000). Communication between Cultures. (3rd Ed.) Beijing: Foreign Language Teaching and Research Press.

Scollon, R. \& Scollon, S. W. (eds.) (2000). Intercultural Communication: A Discourse Approach. Beijing: Foreign Language Teaching and Research Press.

Scotton, C. M., \& Zhu, W. J. (1984). The multiple meanings of Shifu: A language change in progress. Anthropological Linguistics, 326-344. 